\title{
Comunicação
}

[Communication]

\section{Correlação de parâmetros biométricos e produtivos em colônias deMelipona scutelaris}

\author{
[Correlation of biometric and productiveparameters in colonies \\ of Melipona scutelaris] \\ M.C. Silva ${ }^{1}$, J.P. Lopes Neto ${ }^{2}$, N.L. Ribeiro ${ }^{3}$ \\ ${ }^{1}$ Universidade Federal da Paraíba - Bananeiras, PB \\ ${ }^{2}$ Universidade Federal de Campina Grande - Campina Grande, PB \\ ${ }^{3}$ Instituto Nacional do Semiárido - Campina Grande, PB
}

As abelhas sem ferrão, ou meliponíneos, são um grupo de abelhas eussociais, representadas por aproximadamente 600 espécies, sendo 330 dessas encontradas no Brasil, as quais vivem em colônias formadas por fêmeas operárias, princesas, machos e rainha fisogástrica, possuindo uma complexa organização. Em razão da sua capacidade polinizadora, representam um dos principais vetores de polinização da flora silvestre, sendo de extrema relevância ecológica e econômica (Michener, 2013).

A Melipona scutellaris é uma espécie de abelha sem ferrão, encontrada principalmente na faixa litorânea da região Nordeste do Brasil, que prefere habitar locais úmidos, nidificando naturalmente em ocos de árvores. Por apresentar tamanho avantajado e fácil domesticação, são atrativas para a criação comercial. Além disso, essa espécie se destaca das demais melíponas pelo maior valor comercial do seu mel em relação ao da Apis mellifera. Nas regiões tropicais, as características físicas e químicas do mel ainda são pouco conhecidas, visto que a flora apícola é bastante diversificada, associada às taxas elevadas de umidade e temperatura (Alves, 2012).

Em abelhas, as características produtivas são controladas por um grande número de genes. Assim, as características importantes economicamente, geralmente, são correlacionas; dessa forma, o estudo das correlações é necessário (Rinderer, 2008). Além disso, a correlação permite a medida da direção da

Recebido em 5 de agosto de 2019

Aceito em 26 de agosto de 2019

E-mail: maurizetes@hotmail.com relação entre duas características, possibilitando o uso de seleção indireta que, em alguns casos, permite altos ganhos (Cruz, 2001). Em estudos com abelhas, muitas vezes, quantificar características de interesse econômico torna-se difícil, fazendo-se necessário um estudo em termos de colônia que envolva as características que exercem influência de forma direta e indireta (Souza et al., 2002).

A necessidade de explorar cada vez mais o potencial das colônias tornou-se o objetivo da maioria dos meliponicultores que constantemente avaliam o desempenho de suas colônias na tentativa de maximizar a produtividade e minimizar custos e mão de obra (Faquinello et al., 2013). Assim, o objetivo com esta pesquisa foi estimar as correlações entre os parâmetros biométricos e reprodutivos de Melipona scutelaris.

Foram utilizadas 24 colmeias para a coleta dos dados produtivos e biométricos das abelhas. Esses dados foram coletados nos meses de setembro, outubro e dezembro de 2018 e janeiro de 2019, em um meliponário localizado no município de Areia, Paraíba (-6 $55^{\circ} 60^{\prime}$ latitude e $-35^{\circ} 36^{\prime} 60^{\prime \prime}$ longitude). Foram realizadas quatro coletas, com intervalos de 30 dias, consistindo na avaliação de cada colônia, sendo considerados os seguintes parâmetros: tamanho e volume dos potes de mel (TPM e VPM), estimativa da produção de mel (PME), número de favos (NF), diâmetro médio dos favos (DM), altura dos favos (HF), altura das células de cria (HC), número de crias (NC) população (POP) e invólucro de cera nas crias (ICC). 
A metodologia aplicada para a realização das coletas baseou-se nos estudos dos parâmetros biométricos e produtivos realizados por Brito et al. (2013). As coletas foram iniciadas sempre no mesmo horário (7h30), sendo as medições aferidas com o auxílio de um paquímetro digital $150 \mathrm{~mm} / \mathrm{MTX}$, com faixa de medição de $0,01 \mathrm{~mm}-150 \mathrm{~mm}$ e erro de $0,03 \mathrm{~mm}$. Para o volume do mel, foram utilizadas seringas descartáveis graduadas em até $20 \mathrm{~mL}$. Neste estudo, o número de invólucros de cera que envolvem os discos de crias (ICC) foi computado pelo método de contagem simples. Com base nas medidas tomadas, foram realizadas as médias aritméticas para cada colmeia no período experimental.

Para a avaliação das características produtivas, foram computados: o tamanho dos potes de mel (altura e diâmetro) e o volume médio dos potes de mel operculados ( $n=05 /$ colônia). A produção de mel foi estimada para cada colmeia, por meio da contagem dos potes operculados, multiplicando-se o número obtido pelo volume médio de potes de mel encontrados a cada coleta de campo.

A estimativa da população de cada colônia foi obtida pela equação 1:

$$
N C=D M \times N F \times k
$$

em que:

$\mathrm{NC}=$ número de células de cria;

$\mathrm{DM}=$ diâmetro médio dos favos de cria;

$\mathrm{NF}=$ número de favos;

$\mathrm{k}=27$ constante do número de células por área (número de células/diâmetro de favo) para a espécie Melipona scutellaris.

Dessa forma, a estimativa da população (POP) foi obtida segundo a fórmula de Ihering (1932):

$$
P O P=(N C+N C / 2)
$$

em que:

$\mathrm{NC}=$ número de células de crias existentes na colônia.

Os dados foram analisados utilizando-se o PROC CORR do software SAS (2000), utilizando-se o coeficiente de correlação de Pearson.

Não foi observada correlação significativa de HC com nenhuma das características avaliadas ( $\mathrm{P}>0,01$ e $\mathrm{P}>0,05)$. Com base nas correlações das variáveis de produção e biométricas das colônias de Melipona scutellaris, é possível perceber que a variável número de potes de mel (NPM) apresentou maior correlação com TPM, PME, DM, HF, NF, NC e POP, seguido por tamanho de potes de mel (TPM) com: VPM, PME, DM, NC e POP (Tab. 1). A PME apresentou correlação significativa com DM, HF, NC e POP; já o NC apresentou correlação apenas com a POP, enquanto a população está diretamente correlacionada com o DM, a HF e o NC.

Tabela 1. Correlação das variáveis de produção e biométricas das colônias de abelha Melipona scutellaris em colmeias construídas com diferentes tipos de madeira

\begin{tabular}{lccccccccc}
\hline Variáveis & TPM & VPM & PME & DM & HF & HC & NF & NC & POP \\
\hline NPM & $0,54 * *$ & $0,34^{* *}$ & $0,82^{* *}$ & $0,53^{* *}$ & $0,54 * *$ & $0,09^{\mathrm{ns}}$ & $0,53^{* *}$ & $0,56^{* *}$ & $0,56^{* *}$ \\
TPM & - & $0,57^{* *}$ & $0,77^{* *}$ & $0,51^{* *}$ & $0,36^{* *}$ & $0,02^{\mathrm{ns}}$ & $0,37^{* *}$ & $0,49^{* *}$ & $0,49^{* *}$ \\
VPM & - & - & $0,60^{* *}$ & $0,26^{* *}$ & $0,22^{* *}$ & $0,17^{\mathrm{ns}}$ & $0,20^{* *}$ & $0,20^{* *}$ & $0,20^{* *}$ \\
PME & - & - & - & $0,54^{* *}$ & $0,51^{* *}$ & $0,07^{\mathrm{ns}}$ & $0,49 * *$ & $0,53^{* *}$ & $0,53^{* *}$ \\
DM & - & - & - & - & $0,53^{* *}$ & $-0,02^{\mathrm{ns}}$ & $0,54 * *$ & $0,76^{* *}$ & $0,76^{* *}$ \\
HF & - & - & - & - & - & $0,09^{\mathrm{ns}}$ & $0,99 * *$ & $0,68^{* *}$ & $0,68^{* *}$ \\
HC & - & - & - & - & - & - & $-0,04^{\mathrm{ns}}$ & $-0,01^{\mathrm{ns}}$ & $-0,01^{\mathrm{ns}}$ \\
NF & - & - & - & - & - & - & - & $0,69 * *$ & $0,69 * *$ \\
NC & - & - & - & - & - & - & - & - & $1,00^{* *}$ \\
POP & - & - & - & - & - & - & - & - & - \\
\hline
\end{tabular}

NPM= Número de potes de mel; TPM= tamanho dos potes de mel; VPM= volume dos potes de mel; $\mathrm{PME}=$ produção de mel; $\mathrm{DM}=$ diâmetro médio do favo de cria; $\mathrm{HF}=$ altura dos favos; $\mathrm{HC}=$ altura das células; $\mathrm{NF}=$ número de favos; $\mathrm{NC}=$ número de crias; de 32 colônias de Melipona scutellaris.

** Significativo a $1 \% ; *$ significativo a $5 \% ;$ ns = não significativo.

Foram obtidos valores de correlação positivos e significativos, que variaram de 0,20 a 1,00 (Tab. 1). Faquinello et al. (2013) obtiveram valores positivos $(0,19$ a 0,93$)$ e negativos $(-0,36$ a -
0,19). O NPM apresentou o mesmo valor da correlação para o NC e a POP, iguais a 0,56; assim, quanto maior o NPM, maior a quantidade de crias (NC) produzidas, aumentando, desse 
modo, a POP da colônia pelo maior nascimento de abelhas devido à maior quantidade de células presentes no maior número de discos de cria.

A construção de discos de cria pode ser influenciada por vários fatores, incluindo a densidade populacional e a presença de uma rainha (Alves et al., 2009). Quando ocorre oferta de alimento, há um aumento no tamanho dos potes de mel e pólen para um maior armazenamento (Evangelista-Rodrigues et al., 2008). A importância do número de indivíduos se refere ao fato de que, normalmente, em colônias populosas, existem muitas campeiras que coletam mais recursos em épocas de floradas, possibilitando a defesa contra inimigos e a manutenção de temperatura adequada para o desenvolvimento das crias (Faquinello et al., 2013). O NPM também teve alta correlação com o TPM e a HF $(0,54)$ e com o DM e o NF $(0,53)$, como também com a PME $(0,82)$. Porém, teve baixa correlação com o VPM $(0,34)$.

Houve correlação positiva entre o NPM produzido e o DM $(0,53)$. O aumento do número de discos de cria pressupõe um aumento no número de indivíduos na colônia e, com isso, uma intensificação na construção de potes para o armazenamento dos produtos (EvangelistaRodrigues et al., 2008).

A PME teve alta correlação com o NPM $(0,82)$, o TPM $(0,77)$, o VPM $(0,60)$, o DM $(0,54)$, o NC e a POP $(0,53)$, a HF $(0,51)$ e o NF $(0,49)$. A formação de potes com largura e profundidade maiores reduz o espaço ocupado e diminui o consumo de mel pelas operárias na produção de cera, o que leva à maior quantidade de mel produzida, revelando que a produção de mel está diretamente ligada ao número e ao volume de potes de mel (Alves et al., 2012).

Estudos com Apis mellifera demonstraram que a PME é influenciada pela POP (Szabo e Lefkovitch, 1989). Alves et al. (2012) e Faquinello et al. (2013) não encontraram correlação entre a POP e a PME para a espécie Melipona scutellaris. No presente trabalho, foi encontrada correlação $(0,53)$, porém ocorreram outras correlações maiores, confirmando a influência de outras características na produção de mel pelas abelhas melíponas.

Oliveira et al. (2015) avaliaram parâmetros genéticos da abelha Melipona quadrifasciata com base nas características produtivas e biométricas e concluíram que, para esse tipo de estudo, as características NPM, LPM,VPM,APM, NPP, APP, DPP, PM, NDC, LDC,DDC e POP podem ser utilizadas também como critérios de seleção em programas de melhoramento da espécie.

Para futuros estudos utilizando as características produtivas e biométricas das abelhas Melipona scutellaris, podem ser considerados o NPM, o TPM, a PME, o NC e a POP como variáveis respostas.

Palavras-chave: melhoramento de abelhas, meliponíneos, produção de mel

\begin{abstract}
The objective of this research was to estimate the correlations between the biometric and reproductive parameters of Melipona scutelaris. Four collections were performed with 30-day intervals, consisting of the evaluation of each colony, considering the following parameters: honey pot size and volume (HPS and VHP), estimated honey production (EHP), number of combs $(N C)$, mean diameter of the combs $(M D C)$, height of the combs $(H C)$, height of rearing cells $(H R C)$, number of pups $(N P)$ population $(P O P)$ and wax envelope in pups. The data were analyzed using the SAS software (2004), and the Pearson correlation coefficient was used for the correlation calculations. The correlations of the studied variables of production and biometrics of Melipona scutellaris colonies made it possible to perceive that the variable number of honey pots (NHP) present a higher correlation with HPS, EPH, DMC, HRC, NP and POP, followed by size of pots of honey (HPS) with: VHP, EHP, MDC, HC and POP. For future studies using the productive and biometric characteristics of the bees Melipona scutellaris can be considered for EPH, VHP, EPH, NC and POP, as variable responses.
\end{abstract}

Keywords: breeding of bees, meliponines, production of honey 


\section{REFERÊNCIAS}

ALVES, D.A.; IMPERATRIZ-FONSECA, V.L.; SANTOS-FILHO, P.S. Production of workers, queens and males in Plebeia remota colonies (Hymenoptera, Apidae, Meliponini), a stingless bee with reproductive diapauses. Genet. Mol. Res. v.8, p.672-683, 2009.

ALVES, R.M.O.; CARVALHO, C.A.L.; FAQUINELLO, P. et al. Parâmetros biométricos e produtivos de colônias de Melipona scutellaris Latreille, 1811 (Hymenoptera: Apidae) em diferentes gerações. Magistra, v.24, p.105- 111, 2012.

BRITO, B.B.P.; FAQUINELLO, P.; PAULALEITE, M.C. et al. Parâmetros biométricos e produtivos de colônias em gerações de Melipona quadrifasciata anthidioides. Arch. Zootec. v.62, p.265-273. 2013.

CRUZ, C.D. Programa genes versão windows: aplicativo computacional em genética e estatística. Viçosa: UFV, 2001. 648p.

EVANGELISTA-RODRIGUES, A.; GÓIS, G.C.; SILVA, C.M. et al Desenvolvimento produtivo de colméias de abelhas Melipona scutellaris. Biotemas, v.21, p.59-64, 2008.

FAQUINELLO, P.; $\quad$ BRITO, B.B.P.; CARVALHO, C.A.L. et al. Correlação entre parâmetros biométricos e produtivos em colônias de Melipona quadrifasciata anthidioides Lepeletier (Hymenoptera: Apidae). Ciênc. Anim. Bras., v.14, p.312-317, 2013.
IHERING, H.A. Uruçu na apicultura nordestina. Chácaras Quintais, v.46, p.292-296, 1932.

MICHENER, C.D. The Meliponini. In: VIT, P.; PEDRO, S.R.M.; ROUBIK, D.H. (Orgs.). Pothoney: um legacy of stingless bees. New York: Springer, 2013. p.3-17.

OLIVEIRA， K.N.; PAULA-LEITE， M.C.; FAQUINELLO, P. et al. Genetic parameters for production and biometrics traits in honey bee Melipona quadrifasciata anthidioides LEPELETIER. Arq. Bras. Med. Vet. Zootec., v.67, p.819-826, 2015.

RINDERER, T.E. Selection. In: RINDERER, T.E. Bee genetics and breeding. Florida: Academic Press, 2008. p.305-319.

SAS software. Cary: SAS Institute Inc., 2000.

SOUZA, D.C.; CRUZ, C.D.; CAMPOS, L.A. et $a l$. Correlation between honey production and some morphological traits in Africanized honey bees (Apis mellifera). Ciênc. Rural, v.32, p. 869872, 2002.

SZABO, T.I.; LEFKOVITCH, L.P. Effect of brood production and population size honey production of honeybee colonies in Alberta Canadá. Apidologie, v.20, p.157-163, 1989. 